\title{
27 A KNOWLEDGE MANAGEMENT BASED FRAMEWORK AS A WAY FOR SME NETWORKS INTEGRATION
}

\author{
Gerardo Gutiérrez Segura \\ Laboratoire de Productique et Informatique de Systèmes Manufacturiers \\ ggutierr@bat710.univ-lyon1.fr \\ Véronique Deslandres \\ Laboratoire de Productique et Informatique de Systèmes Manufacturiers, \\ deslandres@bat710.univ-lyon1.fr \\ Alain Dussauchoy \\ Laboratoire de Productique et Informatique de Systèmes Manufacturiers \\ dussauchoy@bat710.univ-lyon1.fr \\ FRANCE
}

This paper initially introduces specificities of s mall and medium enterprises (SME) networks, then deals with the recent evolution of the Knowledge Management (KM). In coherence with this evolution, we describe a knowledge management process based on a community of practices which can be applied to these types of groups. The main conclusion is that knowledge management projects provide a good manner for SME networks to facilitate and increase the collaboration rate as well as to share knowledge, allowing them to make collaborative work more efficient.

\section{INTRODUCTION}

A considerable number of computing and social sciences research testify the application of knowledge management (KM) on a large group of enterprises. However in small and medium enterprises (SME) it is also necessary to capitalize the knowledge that could disappear. This need is even more important for strategic SME networks.

The case of SME networks is particular in the sense that generally little time is planned for coordination and collaborative work. By way of consequence, decisions and schedules are made without sufficient consultation and sometimes in a hurry. In this case, some projects of knowledge management are well-adapted. We have been working for six years on the contribution of information technologies (IT) for the co-operation and knowledge division within SME strategic alliances. This research fits into the two GRECOPME projects (GRECOPME, 2000), partially financed by the Rhone-Alpes France's region in which SME's are numerous. These multi-field projects are controlled by l'Ecole Nationale des Mines de Saint-Etienne, and gather teams from Lyon1 and Lyon2, from 1'INSA of Lyon, l'IUT of Roanne and the SaintEtienne University. 
This paper initially introduces specificities of SME networks, then deals with the recent evolution of the Knowledge Management (KM). In coherence with this evolution, we describe a KM process which can be applied to this type of networks in order to enhance partner integration and ensure therefore a better collaboration.

\section{THE UNIQUENESS OF SME NETWORK}

\subsection{Presentation of small and medium enterprises networks}

For more than a decade, many companies have been a iming a lliances in order to develop their activity within a network. Various levels of co-operation and integration can be observed, creating a virtual company. The motivations which lead to firms co-operation are various: offer expansion, introduction on new markets, strategic alliance against competition, etc. For small and medium enterprises, the motivation is still different and can be regarded as defensive or pro-active. Among defensive networks, the objective can be size effect compensation, gap filling, leader's retirement anticipation, etc. The pro-active networks, rarely seen, are created with the strategic aim of expand the offer, to compete, to co-operate on innovation possibilities within a given sector (GRECOPME, 2000).

In SME networks, co-operation intensity strongly depends on the degree of confidence acquired between the companies. We established that these networks had their own life cycle, with three different phases:

- Confidence Construction

- Co-operation Test(s)

- Alliance stabilization (fusion, fragmentation or new alliance)

The coordination and running modes of SME networks are made complex due to the fact that they are not controlled by a single manager but by a group of leaders, even if each enterprises preserving activities with its own customers. Before the final phase of the structure stabilization, the network integration is always considered as potentially reversible by the leaders. But in fact, the more thorough is the co-operation, the more it takes an irreversible character (e.g. company specialization) and the more the company depends on the network. We note that the latter point effectively contradicts leaders' autonomy research. In fact, the firm that comes in a network is rarely a neutral process, and in many cases the integration process itself has to be managed carefully.

As an example, an IT project development aiming at support some of the network activities can be an interesting integration vector, especially if the computer culture of the companies is sufficient (GRECOPME, 2000). Because we have encountered many different cases of IT project, various architectures for the cooperative have been proposed in (Bienner, 1999) and (Gutierrez, 2001). However, the installation of an information system is based mainly on a strong confidence, and it is necessary to wait, in particular in non well-stabilized alliances, until the network succeeded and structured many co-operative activities (objective which is not always reached).

SME networks are organizations where the KM can constitute an undeniable integration v ector towards c o-operating work. Therefore, the setting u p of s everal 
SME network will produce a vast stock of knowledge that will have to be managed in a suitable way. However, at the beginning of such an organization, SME don't especially agree to share information, documents or knowledge with the new partners who may become competitors. We consider that for some SME networks, it can be convenient to set up a co-operation system at the very beginning of the network. Of course such a system will be better a ccepted in firms which a lready have privileged technological culture (e.g. software and computing service companies SCSC). Our approach is based on the aim to provide this confidence by using a structure based on the $\mathrm{KM}$ adapted rather to the managerial problems (little time for coordination and co-operation works, a little confidence etc.) of this kind of networks, i.e., we plan to set up a knowledge management framework in the two first phases of the above-mentioned life cycle.

\section{THE KNOWLEDGE MANAGEMENT}

\subsection{The weak points of the knowledge management}

The main critic that one can make about these tools are that: (1) the majority of them are limited to a particular KM function, (2) the tools do not take into account the company field, and also the standards used, (3) some of these tools were developed specifically for a given company - in general, for a large group and his partners -, this is not very appropriate for other companies, and especially (4) the success of the $\mathrm{KM}$ project associated with the use of a tool is never guaranteed. The large groups even doubt about the effectiveness of this type of project.

The methods of acquisition and capitalization were very criticized when they consider knowledge as an isolated object, not located, described apart from any context and giving their interpretation by a random user (Quéré, 1999). Other methods were developed for the knowledge located, but the complexity of the systems of representation used made the update and the evolution adaptation a very complex and difficult activity (Lucier, 1998).

Overall with regard to the evaluation of the KM projects, certain weaknesses are now well-known, in particular the low visibility of the sources of profitability. Sometimes it's necessary to wait two years to get the benefit from such a project, when it is not purely and simply given up because of the lack of effort of maintenance or maladjustment to the evolution of the company. On the actors level, one notes an increased mobility of the personnel and thus a loss of generalized sincerity, the two phenomena being induced by the market and harming particularly the implication of the actors needed for the development of projects related to the human capital (Meissonier, 1999).

Thus, although our perception of the KM models had evolved since its beginnings, no model economically valid shows how knowledge is connected to the tasks and the performance (Malhotra, 2002). For this reason the role of the leadership is perceived like a weak point in the economy of the knowledge, as well as the role carried to the attention (Von Krogh, 2000): "The managers [...] must learn cognition. On one hand, there is the problem of confidence (based on the exchanges) but also the problem of the attention paid to the individuals". The concept of attention (regard) incorporates and extends the confidence. The exchange 
of tacit knowledge is thus almost impossible without attention. Researchers study for example how to conceive training schemes which would support a behavior of attention. According to our experience, the problem relating to the appropriation by the users of the KM system set up exists indeed, and can be more or less important. Even if the experts having taken part in the project were qualified, the users do not grant confidence in the results obtained only if they estimate that the system does not block their autonomy of decision (Exworth, 2003).

\section{A KM approach for SME Networks integration}

\subsection{Application of KM in SME network}

When we talking about of Knowledge Management for SME's, one can notice that it is not widely used in this kind of companies, mostly because small structures can't follow up with big organizations on the technological level. Nevertheless, a small percentage of SME have some KM activities, and a traditionally accepted limit is that KM concerns companies of more than 40 employees [Lim, 2000]. Indeed, current literature states that KM is more needed by big firms rather than by the small ones, due to the fact that in SME, the problem of knowledge exchange and sharing is lessened by the size of the companies (you know immediately who to ask to), the versatility of employees (making them be concerned by more various subjects) and physical proximity (easier meeting possibilities).This is true for an small enterprise, but the SME networks are out of this context : in an organization, the partners almost don't know each other, are not close to each other, and they are not always disposed to individually expose their knowledge.

Because of this domain's evolution and of our experience with small businesses networks, the benefits of $\mathrm{KM}$ is essentially located in the implementation of procedures - along with technological networks according to the information technologies (IT) culture of the network - , making the knowledge sharing and the collaborative work easier: Interactions and representations exchange, turning hidden knowledge into explicit one. There is also a need for supports for explicit knowledge management (diffusion and explanation of a given representation) as well as for tools designed for creating new knowledge.

The debate about the added value of IT to the organization and particularly to the management of knowledge is regularly brought back on the front scene (Beckman, 1999). Even if the fact that information systems (IS) have a weak impact on the effectiveness of decision making, is widely accepted as soon as only the technical dimension is concerned (data processing) (Simon, 1980), it is still required to evaluate its contribution once all the needs have been defined and that the attention capacity limits of the users have been identified. This attention capacity seems strongly to be related to the IT culture of the company to us, and the IS will play a crucial role for small software and computing service companies; this is the reason why we have chosen to work with this kind of companies. 


\subsection{Software and Computing Service Companies (SCSC)}

In o ur o pinion, $\mathrm{SCSC}$ a re a fertile g round for Knowledge Management. We have many a rguments to defense this a ffirmation. F irstly, technology is in the heart of these companies. Information technologies (IT) characteristics like evolution capacities and obsolescence imply a special and primordial role to knowledge. Indeed, one should not let himself to be outdated by some always evolving technology. One must then continually keep his knowledge and skills up-to-date. The counterpart of evolution capacity is definitely obsolescence. A technology can be quickly seen as out-of-date and be replaced with another one. In order not to be put on the technological fringe, it is required for consultants to keep on learning new technologies, and to acquire new knowledge and know-how. Moreover, we consider it is e asier for an IT-oriented company to develop KM a s it $\mathrm{c}$ annot be $\mathrm{conceived}$ without an "IT Tools" dimension. We understand easily that for the consultants who are working daily with the new computing technologies it is not hard to convince to KM tools.

\subsection{Communities of practice (CoPs)}

In the literature, many authors recognize that many enterprises are using community of practices without being aware of it. The community of practice is a group of individuals who have specified subjects in common interest, which need to interact around problems, which develops an expertise on a field, and which is implied in the objective of collective training (Wenger, 2001). In the beginning, this concept was proposed in response to the technological domination of the efforts in KM works.

It was to make knowledge something alive rather then the reduction of a stored and solidified structure, something that pertains to a community able to maintain, develop, and to share its knowledge. It is the understanding and the management of the tacit knowledge who brought certain authors like Wenger (Wenger, 2002) to base CoPs on the relational and social nature of knowledge. This approach has been successfully used in the private sector over the past decade and now being applied in the public sector (Snyder, 2003). By the other hand Community Portals also exist including a set of functionalities (Schneider, 2002), such as the management of contents, interactions, of the community as well as different mechanisms of piloting, including for example the reputation system.

We have chosen communities of practice, which according to our opinion seems provide the appropriate environment for the generation and the transfer of knowledge of work between network partners.

\subsection{A community practices instead of Knowledge Management system.}

In the current marketing strategy, the software editors do not hesitate to qualify any new functionality which allows the management of documents in $\mathrm{KM}$, the same for $\mathrm{KM}$ for the SME. Although the information management and the knowledge management share the same supports (documents, plans, diagrams), their evolution, their objectives and their operating ways are completely different (Malhotra, 1998).

Our method consists in the development of a community of practice where the actors will share information, ideas, documents, etc. with the aim of increasing their 
own knowledge level, and ensure the correct broadcast of technical information to the persons which need it. In other words, rather than study the wealth of information in the channel of communication, it is interesting to make an analysis of the dynamics of the organization. This is particularly true within SME networks which support the co-construction of strategic directions especially based on exchanged information. The work on knowledge management resulting from human resources recommend that everybody reached the knowledge level at the time that everybody connect actors who communicate. More precisely, we consider that knowledge is the result of the interaction between information (a procedure, information of a customer, an opinion of a colleague) and a person. Indeed by the interpretation process according to the actors that the information is transformed in knowledge.

For the creation of our CoPs, we based ourselves on the four stages of development of the communities of practice proposed by Wegner (Wenger, 2001):

The field: Naturally, it is essential to know on which field the sharing of knowledge of the community is centered. For this point we chose the computing field, in particular on the development of web sites and office applications on which all partners of the group are concerned.

The operation: Rather than an organization of operation of the community we must cultivate it (Prax, 2003). Indeed the evolution of the community practices is organic. However a minimum of organization seems to need. It is necessary that people s hould be e ngaged to the community to g ive him a minimum of stability, points of reference and that will be the reference persons. Being that we work with a SME network geographically away.

The actions: A community usually shares common activities and also some own projects. These types of activities, technological tools, external sources to exploit, etc., should be defined. In the SCSC network that we are working with, the information objectives and knowledge exchanges has been defined with the partners. We identified two main objectives for the starting the community. These objectives were related to new information technologies as well as some projects actually being pursued by the network. Indeed, our purpose is to share a special kind of knowledge, in particular relationship knowledge which concern the actors of the fieldwork. Example the different kinds of knowledge that will be shared where several partners of the group take part: information about the new software for the Internet site development, the way of how protecting a computer against a virus propagated by the Net, but also about information about how to manage the project of setting-up a ERP in a SME society etc.

The tools: They correspond to the whole physical and technological device that facilitates the running of the community. The objective of our approach is to make the most of the powerful technologies to be easy to use for the participants of the community, it permitted us the specification of the computing tools, support tools (a Wiki and a forum) as well as the establishment of use recommendations. Indeed, this community is based on a Wiki and a forum. The Wiki is a piece of a server of applications which permits to create as well as to publish Web contents using as a tool a navigator Web. For instance, Wiki permits the collective creation of documents hypertext : it is about " Open Editing " in reference to Open Source (of the opened editorial content). Wikis are often created in co-operation with other 
internauts. Anybody can modify a page (a minimum of computer knowledge is required). Every participant has liberty to edit wiki. In our method, we implemented the Wiki and then we only allowed access to members of the community.

The main use of the Wiki is the publishing in order to share knowledge in relation to the new domains among members of the group (and therefore, the knowledge of the actors increases very quickly) so that each one of the partners knows domains of expertise of the others. Activities of administration made in the beginning of the project aimed mainly to launch demands regarding to some domains so that members publish in the Wiki these knowledge, information, experiences, links towards the interesting sites, etc. on the required theme. Thus, as administrators we first created the basis of a page on the theme to develop on the Wiki, and then we sent an e-mail to the group to invite them to participate.

It took for the forum a couple of months to start. Actually, the main function of the forum in the beginning of the activities was to be the support of communication of the group (an e-mail of the group). However, it became afterwards a real forum of sharing on different domains. Indeed, some questions answered to questions but launched other questions in order to complete, so participants answered to these new topics. These first activities allowed the group to introduce themselves (especially about the other participant expertise), but to our opinion, the most important thing was the creation of a confidence climate that grew up dramatically in a short time thanks to the constant communication and sharing relations. For example: activities as asking information directly to other partner on the forum as well as to express points of view in relation to answers or themes treated on the $W$ iki b ecame very current for all participants.

\section{CONCLUSIONS}

We have introduced a methodology for a KM system within SME networks which can run at the beginning of co-operating activities. The objective of this research is to propose a solution closely suitable for the problematic of SME networks towards knowledge sharing. We estimate that the KM field for the SME networks is not explored enough by the scientific communities. The objective of this research is to stimulate the integration and co-operation to increase the confidence (which has an very low level at beginning of activities) within such organization, especially using the existing and scattered knowledge capital of the network.

This research was at first based on the analysis of the problematic of integration and sharing existing in these organizations. Then we applied the feed-backs of related works from the knowledge management community. We are aware that the mere installation of certain technologies will not guarantee the success of projects of knowledge management in SME networks, because the management and strategic approach remain fundamental. Nevertheless a global co-operative technological culture is appearing due to everyday internet use by professionals. Our purpose is that the KM within SME network can be applied gradually, aiming to develop a learning organization (Jacob, 2000). Due to their structure -a group of small size organizations -, to co-operation imperatives not always precisely formalized, and to the necessary up-date regarding computer technologies, SME networks provide an auspicious natural setting for the use of the new knowledge economics. 


\section{REFERENCES}

1. Beckman, T. (1999) "The Current State of Knowledge Management", in Knowledge Management Handbook, edited by Jay Liebowitz, CRC Press, Boca Raton, Floride, 1.1-1.21

2. Biemner, F. and FAVREL J. (1999) "Organization and management of a distributed information system shared by a pool of enterprises". Acts of the conference IEPM'99. Glasgow, Juillet 1999.

3. Exworth, M., Wilkinson, E. K. McColl, A., Moore, M., Roderick, P., Smith, H. and Gabbay, H. (2003) "The role of performance indicators in changing the autonomy of the general practice profession in the UK", Social Science \& Medicine, Vol. 56, Issue 7, 1493-1504.

4. GRECOPME (2000) Vincent L. et al, "Groupement d'Entreprises Coopérantes : Potentialités, Moyens, Evolutions", Rapport du projet de la Région Rhône-Alpes 1997-2000

5. Guffond, J.L. ; Leconte, G. (1998) "Logistique de chantier, modes d'organisations et outils de pilotage - le cas de l'activité de construction", Acts of the second international meetings of research en logistique, "Logistique et interfaces organisationnelles", édité par N. FABBE-COSTES et C. ROUSSAT, Marseille, January 27-28.

6. Gutierrez-Segura, G. (2001) 'ERP pour les groupements de PME/PMI', Rapport du DEA ISCE (Informatique et Systèmes Coopératifs pour les Entreprises) Univ. Claude Bernard LYONI.

7. Jacob R. et S. Turcot (2000) "La PME «apprenante ": Information, connaissance, interaction, intelligence", Rapport de veille, projet Globalisation et PME innovante, Université du Québec à Trois-Rivières, Juillet, 113p..

8. Lim, D. and Klobas J. "Knowledge management in small enterprises" The Electronic Library, volume 18 , nombre 6, 2000. http://www.emerald-library.com

9. Lucier, C.E. and Torsilieri, J.D. (1998) "Why Knowledge Programs Fail: A C.E.O.'s Guide to Managing Learning", article web visible sur http://www.it-consultancy.com /extern/extern.html (visible le 26 Juin 2003).

10. Malhorta, Y. (1998) "Deciphering the Knowledge Management Hype", Journal for Quality \& Participation, Special issue on Learning and Information Management, 21, 4, 58-60.

11. Malhorta, Y., (2002) "Why Knowledge Management Systems Fail? Enablers and Constraints of Knowledge Management in Human Enterprises". In Holsapple, C.W. (Ed.) Handbook on Knowledge Management 1: Knowledge Matters, Springer-Verlag, Heidelberg, Germany, 577-599.

12. Meissonier, R., (1999) "NTIC et processus de décision dans les PME-PMI", rapport de recherche WP n561, LAE Aix-Marseille

13. Prax, J.Y. "Le manuel du knowledge management: une approche de 2e génération"'. Paris: Dunod, 2003.

14. Nonaka, I. and Takeuchi, H. (1995) "The Knowledge-Creating Company", Oxford, Oxford University Press

15. Querel, L. (1999) “Action et cognition situées", Conférence Publique 17 juin 1999, Montpellier

16. Scheinder, D. (2002) "Portail pour les communautés de pratiques", TECFA (Technologies de Formation et Apprentissage) FPSE (Faculté de Psychologie et des Sciences de l'Education) Université de Genève.

17. Simon H. A. (1980) "Le nouveau management, la décision par les ordinateurs", Economica, Paris. Lakatta EG, Cohen JD, Fleg JL, Frohlich ED, Gradman AH. Hypertension in the elderly: age- and disease-related complications and therapeutic implications. Card Drugs Ther 1993; 7: 643-54.

18. Snyder W. M. et al (2003) "Communities of practice: A new tool for Government Managers", http://www.businessofgovernment.org/pdfs/Snyder_report.pdf

19. Von Krogh, G., Ichijo, K. and Nonaka, I, (2002) "Enabling Knowledge Creation: How to Unlock the mystery of tacit Knowledge and Release the Power of Innovation" Oxford university press, N.Y.

20. Wenger, Etienne. (2001). "Supporting Communities of Practice: A Survey of Community-oriented Technologies". Published as "shareware" and available at www.km.gov under "Group Documents", then "Documents and Resources."

21. Wenger, E. McDermott, . R. et W. Snyder (2002). "A guide to managing knogledge : Cultivating Comunities of Practice", Harvard Business School Press. 